\title{
Pengembangan Sistem Informasi Marketing dengan Model B2C (Business To Consumer) Pada Minno Barbershop
}

\author{
Deva Candra Wijaya ${ }^{1 *}$, Agung Riyantomo ${ }^{2}$ \\ Jurusan Teknik Informatika, Fakultas Teknik, Universitas Wahid Hasyim \\ Jl. Menoreh Tengah X/22, Sampangan, Semarang 50236. \\ "Email: Devacandrawijaya@gmail.com
}

\begin{abstract}
Abstrak
Usaha Marketing berbagai macam barang dan jasa adalah salah satu pusat ekonomi Indonesia yang tahan goncangan dan resesi. Pemasaran umumnya berangkat dari usaha yang berakar pada budaya dan kekhasan suatu daerah. Tren terbaru menunjukkan bahwa pemasaran saluran omni berkembang pesat. Preferensi pelanggan terhadap transaksi digital mendorong perusahaan untuk mengubah platform mereka ke pemasaran digital. Saat ini, pelanggan mencari informasi lebih lanjut, mempelajari produk, membeli atau berbelanja secara online. Pelanggan menjadi semakin mobile dan secara digital marketing. Mereka berpindah dari satu saluran ke saluran lainnya, dari offline ke online. Pertama menganalisis faktor - faktor apa saja yang mendorong pemsaran produk untuk menggunakan e-commerce. Analisis beberapa faktor pendorong ini dilakukan dengan metode waterfall. Metode ini cocok untuk pengembangan perangkat lunak dengan spesifikasi yang tidak berubah-ubah". Model SDLC air terjun (waterfall) sering juga disebut model sekuensial linier (sequential linear) atau alur hidup klasik (classic life cycle).
\end{abstract}

Kata kunci: Akurat, Barbershop, Efisien, Informasi, Marketing.

\section{PENDAHULUAN}

Transaksi

pemesanan

online meningkatkan komunikasi terbuka antara mitra sepanjang rantai nilai dan menawarkan model bisnis yang terintegrasi dimana perusahaan dapat menjadi responsive, fleksibel terhadap perubahan kebutuhan pasar dan pelanggan.

Dengan pertumbuhan sistem online yang sangat pesat maka sangat penting untuk mengetahui bagaimana interaksi antara manusia dan komputer pada website barbershop tersebut. Perusahaan dan pembisnis berusaha untuk memaksimalkan pendapatan mereka dengan menyediakan tidak hanya produkproduk berkualitas secara garis besarnya juga membuatnya mudah untuk memesan dan berinteraksi dengan sistem online. Penerapan penggunaan sistem informasi bisa dimanfaatkan dengan baik melalui banyak hal. Salah satunya penerapan sistem informasi dalam dunia bisnis yang dapat membantu para pelaku pembisnis dalam melakukan pengelolaan dan penyebaran informasi untuk mencapai tujuan bisnis yang diinginkan.

Menurut Khoirun (2018) online marketing merupakan kegiatan komunikasi pemasaran dengan menggunakan media Internet. Pada awalnya menggunakan halaman- halaman statis berformat HTML yang bisa diakses oleh pengguna Internet. Itulah awal dari website yang kemudian menjadi semacam 'brosur online' dan bahkan 'kantor kedua' bagi perusahaan-perusahaan untuk menampilkan jati dirinya ke seluruh dunia.Internet marketing atau e-marketing atau online-marketing adalah segala usaha yang dilakukan untuk melakukan pemasaran suatu produk atau jasa melalui atau menggunakan media Internet atau jaringan World Wide Web.

Hasil dan kesimpulan dari penulis ini adalah e-commerce dapat dijadikan sebagai media promosi, mempermudah proses penjualan yang dilakukan secara online, serta dapat mempermudah dalam pengolahan data dan pencetakan laporan yang tidak lagi memerlukan pencatatan dalam bentuk arsip.

Penelitian sebelumnya pernah dikerjakan oleh (Welim dkk, 2017) mengenai Rancang Bangun Sistem Informasi Jasa Barbershop dan Coffee pada Gentlemen Barbershop and Coffee. Penelitian ini menghasilkan sebuah sistem informasi berbasis desktop mengenai jasa pemesanan barbershop dan coffe. Perbedaan dengan penelitian yang dikerjakan ini berbasis web. 


\section{KAJIAN PUSTAKA}

\subsection{Sistem Informasi}

Menurut Jogiyanto (2005) Informasi sangatlah penting artinya bagi suatu sistem, karena tanpa adanya informasi sebuah organisasi akan lemah dan akhirnya runtuh. Informasi dapat didefinisikan sebagai berikut : Informasi adalah data yang diolah menjadi bentuk yang lebih berguna dan lebih berarti bagi yang menerimanya.

Informasi dikatakan berguna apabila mempunyai kualitas yang baik bagi pengambilan keputusan untuk mencapai tujuan tertentu. Kualitas informasi sangat dipengaruhi atau ditentukan oleh tiga hal, yaitu:

1) Akurat (Akurate)

Informasi tersebut adalah bebas dari kesalahan dan memiliki maksud yang jelas.

2) Tepat Pada Waktunya ( Time Lines)

Tepat waktu berarti informasi tidak boleh terlambat untuk sampai kepada penerima, karena informasi yang telah usang akan berpengaruh tidak baik terhadap pengambilan keputusan.

3) Relevan (Relevancy)

Informasi harus relevan atau mempunyai hubungan dengan masalah yang akan diselesaikan dan mempunyai manfaat bagi penerimanya.

\subsection{Pengertian Marketing}

Menurut Blythe (2005) marketing merupakan istilah yang diberikan pada semua aktifitas yang terjadi antara individu atau perusahaan dengan pelanggan.Ini merupakan konsep mendasar dari sebuah pasar, dimana penjual dan pembeli melakukan transaksi yang saling menguntungkan.

Dua istilah lain dari pemasaran yang paling banyak digunakan adalah:

1) Pemasaran merupakan proses manajemen yang mengidentifikasi, mengantisipasi, serta memenuhi kebutuhan pelanggan secara efisien dan menguntungkan. (UK Chartered Institute of Marketing).

2) Pemasaran merupakan proses perencanaan dan konsep pelaksanaan, penetapan harga, promosi dan distribusi gagasan atas barang dan jasa untuk menciptakan pertukaran

3) dalam rangka memenuhi kebutuhan individu dan organisasi. (American Marketing Association ).

\subsection{Jasa Barbershop}

Jasa barbershop merupakan sebuah usaha jasa pangkas rambut khusus pria dengan gaya modern dan mengikuti trend anak muda saat ini. Barbershop ini memberikan keunggulan bagi para usahawan karena usaha yang ditawarkan mengedepankan suasana yang bersih, nyaman dan potongan rambut rapi bagi para pengunjung.

\subsection{Metode Waterfall}

Model SDLC air terjun (waterfall) sering juga disebut model sekuensial linier (sequential linear) atau alur hidup klasik (classic life cycle). Model air terjun menyediakan pendekatan alur hidup perangkat lunak secara sekuensial atau terurut dimulai dari analisis, desain, pengodean, pengujian, dan tahap pendukung (support).

Dengan bahasa pemrograman PHP dan HTML database yang digunakan adalah MySQL. Diharapkan dengan sistem informasi dan transaksi yang berbasis ecommerce ini dapat mengurangi biaya yang dikeluarkan untuk pemasaran produk, promosi, serta mampu meningkatkan kegiatan pemasaran Minno Barbershop menjadi lebih efektif dan efisien tanpa harus ke tempat usaha secara langsung. Secara garis besar, teknik yang digunakan dalam penerapan metode waterfall, seperti yang ditunjukkan pada gambar 1 .

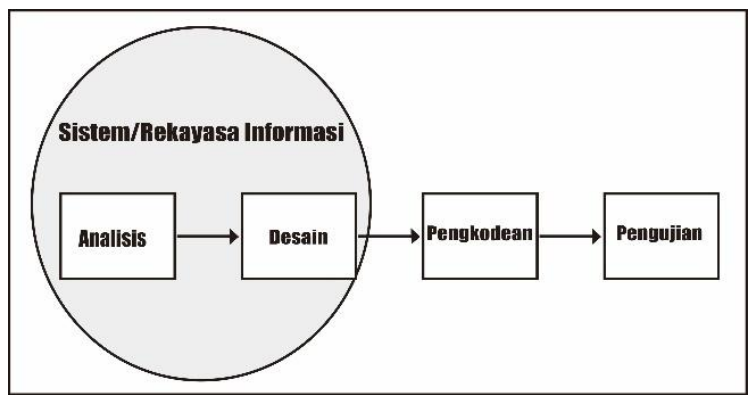

(Sumber: Rekayasa Perangkat Lunak, Sukamto ()

\section{Gambar 1. Metode Waterfall}

\subsection{Software Pendukung}

Sesuai dengan keinginan user atau brainware yang memberikan perintah kepadanya. Penulis menggunakan software yang digunakan dalam pembuatan sistem informasi dan transaksi marketing berbasis website antara lain:

1) CorelDRAW

2) XAMPP 

3) Adobe Dreamweafer CS6
4) Notepad
5) Mozilla Firefox
6) Adobe Photoshop

\subsection{Tinjauan Objek}

Nama Instansi : Minno Barbershop

Alamat Instansi : Jalan Beruang Dalam Timur 2 nomer 14, Kalicari Semarang.

Telepon : 081548255608

\section{METODE PENELITIAN}

\subsection{Metode Pengumpulan Data}

Metode pengumpulan data adalah faktor terpenting yang harus dipenuhi untuk dianalisis dan diolah. Pengumpulan data bertujuan untuk memperoleh informasi yang dibutuhkan untuk menyelesaikan penelitian ini.

Dalam pengumpulan data dan informasi adapun metode yang digunakan yaitu:

\section{a. Metode Observasi}

Di tahap ini, penulis melakukan pengumpulan data dengan pengamatan dan pencatatan mengenai hal-hal yang diselidiki secara langsung di Minno Barbershop yang terletak di Jalan Beruang Dalam Timur 2 nomer 14, Kalicari Semarang.

\section{b. Metode Wawancara}

Di tahap ini, penulis mengumpulkan data secara langsung dengan melakukan komunikasi tanya jawab langsung terhadap pemilik meliputi proses kegiatan yang terjadi dari sisi pemilik barbershop dan komunikasi tanya jawab langsung terhadap penghuni, untuk melengkapi kebutuhan informasi yang akan digunakan dalam mengembangkan informasi.

\section{c. Metode Kepustakaan}

Di tahap ini penulis melakukan pengumpulan data dengan membaca jurnal, media online dan skripsi terkait pengembangan media informasi sebagai referensi dan landasan teori.

\subsection{Alur Sistem}

Agar memudahkan pemahaman alur sistem yang ada maka digambarkan dalam bentuk diagram alur atau yang sering disebut Flowchart. Berikut gambaran alur sistem informasi minno barbershop:

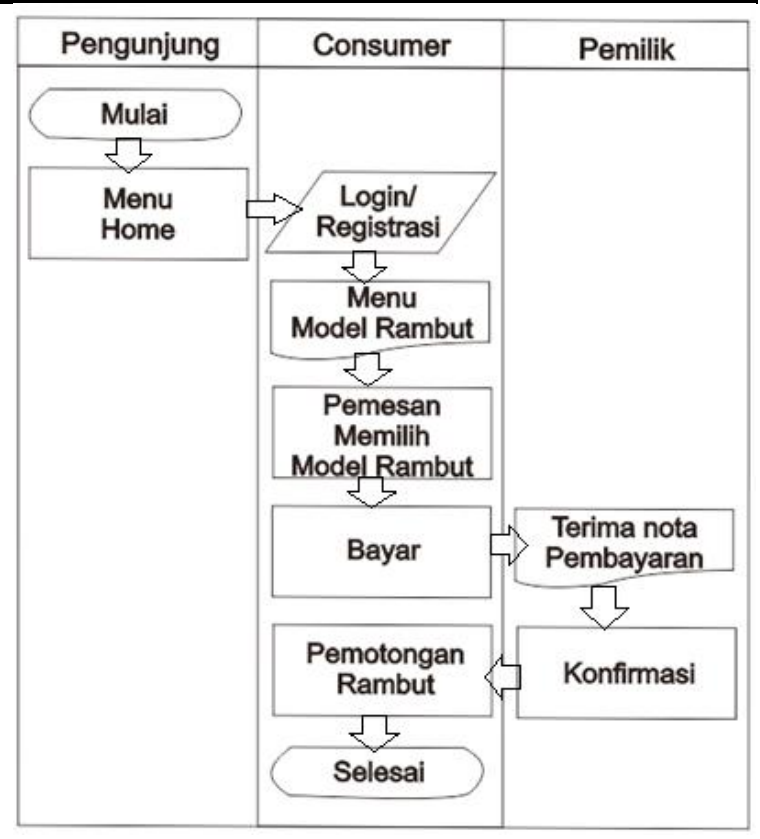

Gambar 2. Flowchart Sistem

Gambar di atas merupakan flowchart untuk memudahkan pemahaman. Mulai untuk menjalankan program, lalu akan muncul menu home kemudian login dengan memasukkan id dan password lalu setelah itu pada tahapan selanjutnya akan dibawa ke menu transaksi, jika memilih menu model rambut maka akan menambahkan pilihan anda di halaman keranjang belanja kemudian detail (edit) model dan kita bisa menginput, mengedit dan menghapus produk yang kita inginkan. Setelah selesai transaksi maka kita langsung menuju menu pembayaran, dan kemudian masuk ke data pemilik barbershop, Setelah semua persyaratan selesai maka akan di konfirmasi pemilik barbershop dan selesai.

\section{HASIL DAN PEMBAHASAN}

Tahap ini akan menjelaskan beberapa hasil uji coba terhadap sistem yang telah diimplementasikan sebelumnya dari tahap perancangan dan implementasi. Hasil dari apa yang telah dibuat sebelumnya disini adalah berupa sebuah sistem yang mampu membantu calon member melakukan pemesanan secara online dan membantu pemilik minno barbershop untuk mengelola pembayaran dengan mudah.

Penulisan kode-kode pemrograman sistem dapat dilihat di lampiran kode-kode pemrograman. Antarmuka dari sistem yang 
dibuat berdasarkan rancangan sebelumnya dapat dilihat sebagai berikut:

1. Halaman logo utama minno barbershop

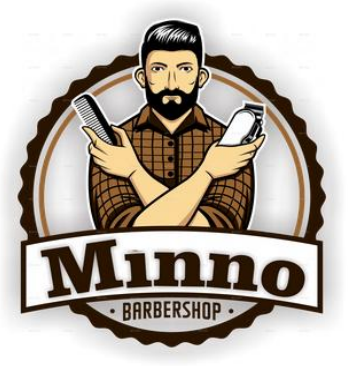

\section{Gambar 3. Halaman logo utama}

Di halaman ini merupakan tampilan antarmuka logo di halaman utama minno barbershop.

\section{Halaman beranda}

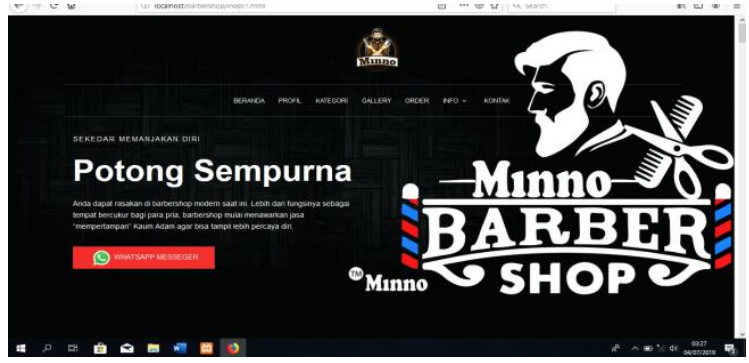

\section{Gambar 4. Halaman beranda}

Di gambar V.2 halaman ini merupakan tampilan antarmuka menu utama minno barbershop. Menu utama minno barbershop akan tampil setelah user klick logo di halaman logo depan website.

\section{Halaman menu user}

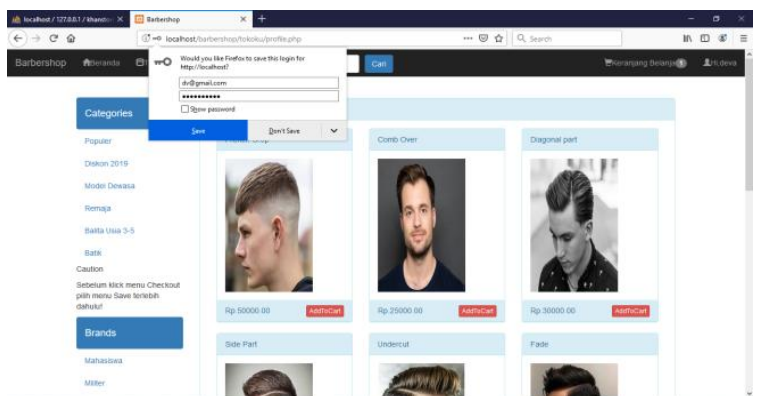

Halaman V.3 ini user langsung dihadapkan dengan gambaran dari minno barbershop yang menampilkan list model rambut beserta harganya, di halaman ini juga user dapat langsung mengecek ketersediaan model rambut yang diinginkan kemudian menginputkan model rambut sesuai selera.

4. Halaman cart (keranjang) model rambut

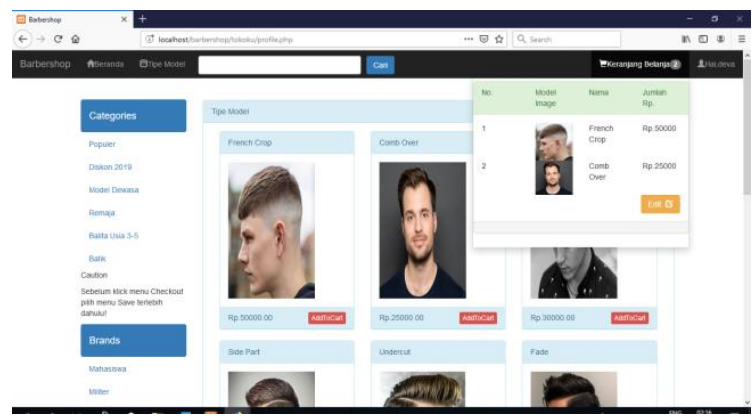

Gambar 6. Cart (keranjang) model rambut

Halaman ini akan muncul setelah user menginputkan model rambut yang diinginkan, halaman ini menampilkan ketersediaan model rambut sesuai dengan inputan/output oleh user.

5. Halaman detail pemesanan

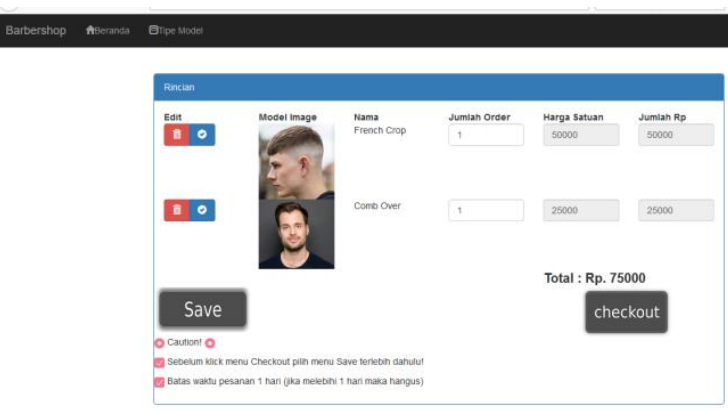

\section{Gambar 7. Halaman detail pemesanan}

Halaman ini menampilkan detail pemesanan user dimana menampilkan nama model ,gambar model rambut, jumlah order, harga satuan, dan total yang berfungsi memastikan pemesanan yang akan diinputkan sesuai dengan yang diinginkan user. Pemesanan mempunyai jangka waktu satu hari.

Gambar 5. Halaman menu user 
6. Halaman upload pembayaran consumer

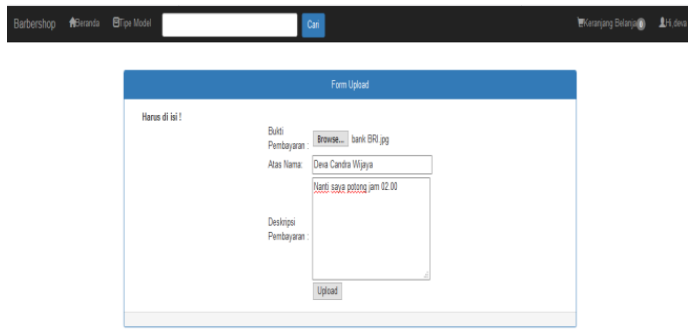

\section{Gambar 8. Halaman upload pembayaran consumer}

Di halaman ini member dapat mengupload bukti pembayaran sebagai bukti pembayaran yang letah dilakukan, untuk selanjutnya pembayaran tersebut dikonfirmasi oleh admin.

\section{Halaman pemberitahuan sukses di upload}

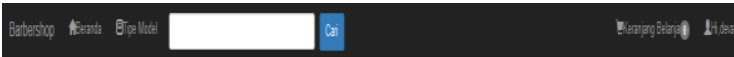

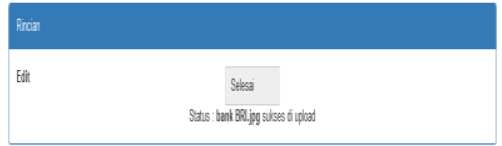

\section{Gambar 9. Halaman pemberitahuan sukses} di upload

Di halaman ini member dapat melihat stasus sukses upload bukti pembayaran untuk selanjutnya pembayaran tersebut dikonfirmasi oleh admin.

8. Halaman selesai transaksi pemesanan
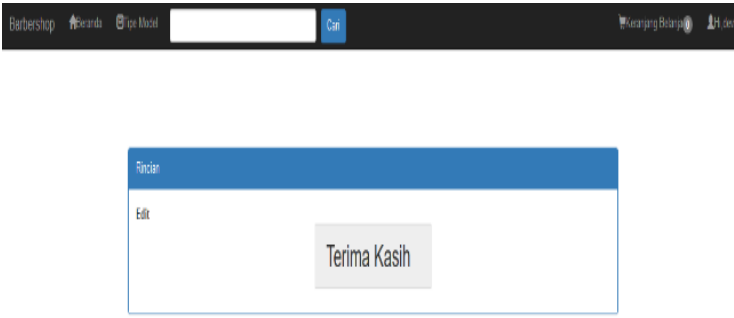

\section{Gambar 10. Halaman selesai transaksi pemesanan}

Di halaman ini member dapat mengupload bukti pembayaran sebagai bukti pembayaran yang letah dilakukan.
9. Halaman kontak
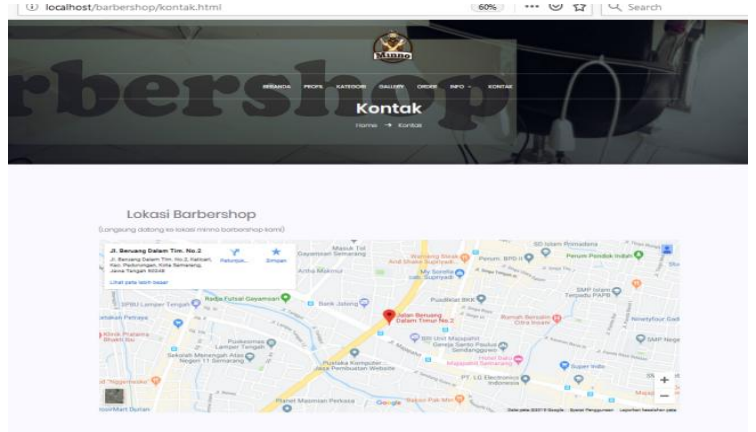

Gambar 11. Halaman kontak

Halaman ini menampilkan maps pemesanan user dimana menampilkan lokasi minoo barbershop dan email agar bias berkomunikasi secara langsung mengenai model, gambar model rambut, jumlah order, harga satuan, dan total.

10. Jasa Admin (pemilik)

Halaman utama login admin

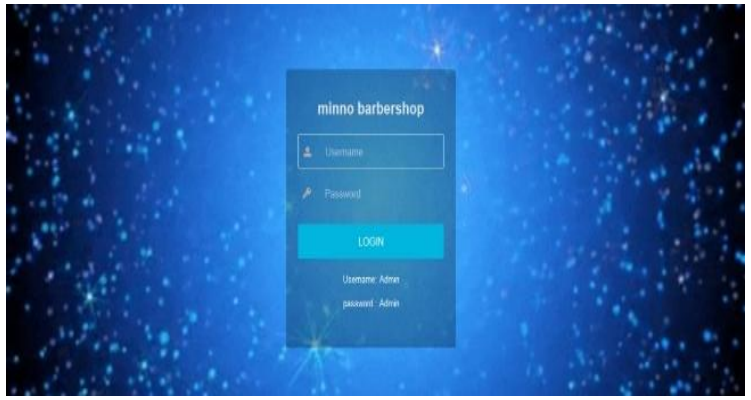

Gambar 12. Halaman utama login admin

Di halaman ini admin dapat masuk menggunakan username dan password yang sudah disediakan.

\section{Halaman menu setelah login}

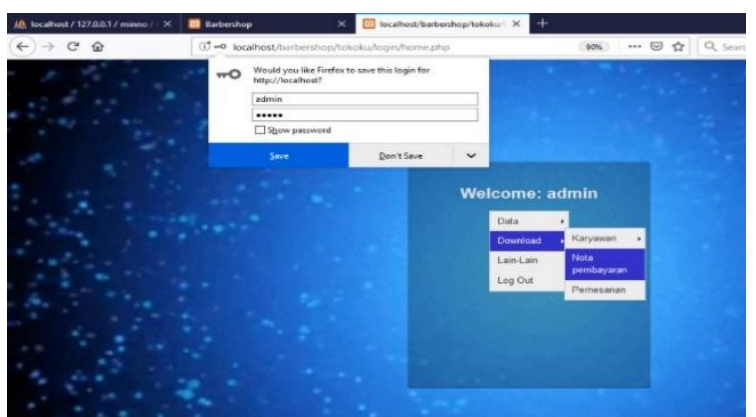

Gambar 13. Halaman menu setelah login 
Di halaman ini admin dapat memilih menu yang tersedia.

\section{Halaman Bukti Pemesanan}

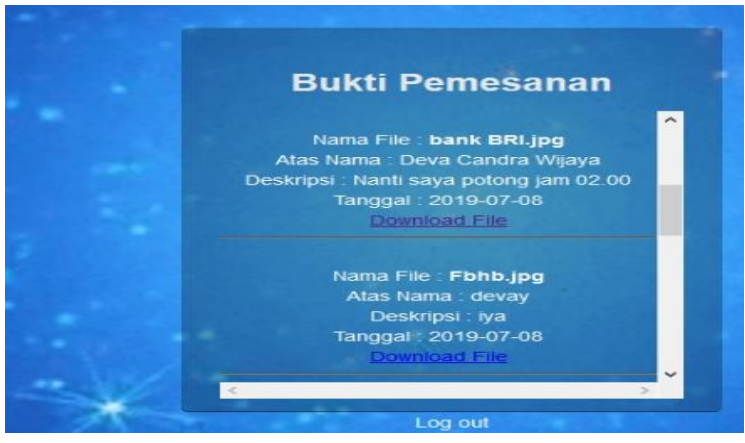

\section{Gambar 14. Halaman bukti pemesanan}

Di halaman ini menampilkan detail pemesanan consumer beserta konfirmasi pemesanan dan konfirmasi pembayaran, Setelah admin melihat daftar pembayaran member kemudian klik download sesuai nama member maka akan diarahkan ke halaman histori pembayraan yang telah dilakukan member, dihalaman ini menampilkan periode pembayaran bukti, tanggal bayar, keterangan dan dapat melakukan cetak pembayaran tiap periode.

\section{Halaman proses simpan file}

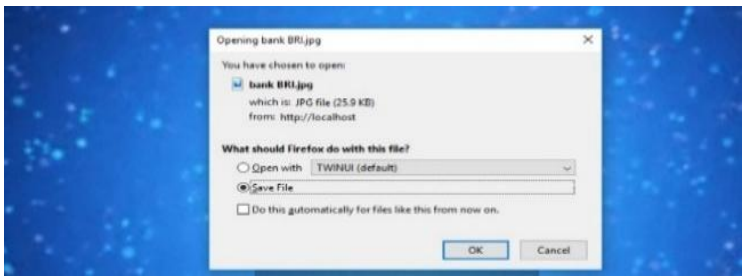

Gambar 15. Halaman proses simpan file

14. File yang sudah di download

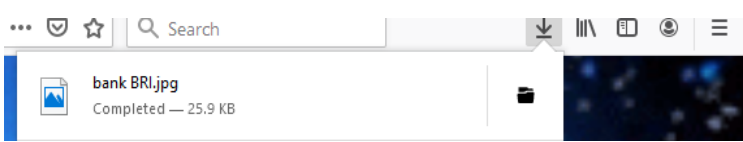

Gambar 16. File yang sudah di download

Di halaman ini menampilkan detail pemesanan user beserta konfirmasi pemesanan dan konfirmasi pembayaran, di halaman ini juga user dapat membatalkan pesanan asalkan pemesanan tersebut belum dilakukan pemotongan rambut oleh pemilik.

\section{KESIMPULAN DAN SARAN}

Berdasarkan hasil pengembangan sistem yang telah penulis lakukan, penulis mencoba membuat suatu kesimpulan dengan menyantumkan beberapa saran yang berhubungan dengan pembahasan yang telah dihasilkan sebelumnya.

\subsection{Kesimpulan} berikut:

Kesimpulan dalam penelitian ini sebagai

1. Dengan adanya Sistem Informasi Marketing diharapkan dapat mempermudah user dan consumer untuk berkomunikasi di luar jadwal perusahaan.

2. Dengan adanya media informasi ini diharapkan sangat membantu pihak perusahaan khususnya dalam proses pemasaran, pengolahan data, pemesanan jasa, data member dan data pembayaran.

\subsection{Saran}

Saran berdasarkan kesimpulan yang telah diuraikan sebelumnya sebagai berikut:

1. Dibuatkan lebih banyak fitur seperti pilihan bahasa, agar tampilan website lebih sempurna.

2. Membackup data-data setiap waktu yang sudah tersimpan agar lebih aman.

Penulis berharap di pengembangan sistem informasi selanjutnya dalam proses pencarian di google menggunakan algoritma tertentu agar mendapatkan hasil pencarian yang teratas dan maksimal.

\section{DAFTAR PUSTAKA}

Blythe, J. and Zimmerman, A., (2005) Business to Business Marketing Management: A Global Perspective, Thomson, London , Vol.4 No.1, 312 p.

Jogiyanto, H.M., (2005), Analisis dan Desain:

Sistem Informasi Pendekatan dan Praktik Aplikasi Bisnis, Penerbit Andi, Yogyakarta.

Khoirun Nisa, Aris Laili, Syifaul Qolbiyatul, Mohammad Suyanto., (2018), Strategi Pemasaran Online Dan Offline, Jurnal Karya Pengabdian Dosen dan 
Vol. 3, No. 1, Maret 2021, Hal. 30-36

Mahasiswa, Surabaya Vol 01 No 1, EISSN : 2655-9706.

Sukamto, Rosa A, dan Shalahuddin M. (2014), Rekayasa Perangkat Lunask Terstruktur dan Berorientasi Objek, Bandung: Informatika Bandung.

Welim, Y., \& Afifi, A. (2017). Rancang Bangun Sistem Informasi Jasa Barbershop dan Coffee pada Gentlemen Barbershop and Coffee. Budi Luhur Information Technology, 14(2) 